\title{
MicroRNAs Role in the Central Nervous System Development and Abnormalities
}

\section{Fang Liu* and Cheng Wang}

National Center for Toxicological Research/U.S. Food and Drug Administration, USA

"Corresponding author: Fang Liu, Division of Neurotoxicology, National Center for Toxicological Research/U.S. Food and Drug Administration, Jefferson, AR 72079, USA, Tel: +8705437259; E-mail: Fang.Liu@fda.hhs.gov

Received date: July 19, 2016; Accepted date: July 21, 2016; Published date: July 27, 2016

Copyright: (c) 2016 Liu F, et al. This is an open-access article distributed under the terms of the Creative Commons Attribution License, which permits unrestricted use, distribution, and reproduction in any medium, provided the original author and source are credited.

\section{Editorial}

Initially, non-coding RNAs were thought to be "junk RNAs". MicroRNAs (miRNAs), a group of small non-coding RNA molecules, were discovered in 1993 [1,2]. However, their functions have been found to be associated with diverse biological procedures, including development, metabolism, immunity, hematopoietic differentiation, etc. [3]. It is estimated that miRNAs regulate the activity of approximately $60 \%$ of human protein-coding genes [4]. Abnormal miRNA expression may lead to a number of diseases, such as neoplasms [5,6], age-related diseases [7], and neurological disorders [8]. Advances in miRNA research have suggested that miRNAs not only help to understand molecular mechanisms of human CNS diseases, but also have potential to serve as biomarkers for early detection of neurological and/or neurodegenerative alterations.

\section{miRNAs in the Central Nervous System (CNS)}

Around $70 \%$ of the identified miRNAs are found in the brain [9]. Some miRNAs are specifically expressed and enriched in brain [10], suggesting their specific roles in regulating brain functions. Specifically, miRNAs are implicated in brain development: they regulate embryonic neural induction, development, differentiation, neuronal subtype specification, migration and integration, synaptogenesis and synaptic plasticity [11]. Any interference of miRNA regulations may be associated with aberrant neural development and neurological disorders.

The strikingly regulatory effects of miRNAs on the brain during development vary depending on developmental stages and/or the specific brain regions $[10,12-14]$, contributing to the balance between neural stem cell proliferation and differentiation, therefore directing neural cell fates and brain morphogenesis. In general, miR-124, miR-125b, miR-137, miR-7 are contributing to neuronal differentiation, whereas miR-134, miR-184 are effective in maintaining neural stem cells at the undifferentiated status $[15,16]$. Indeed, miR-124 has been demonstrated to be the most abundantly expressed in adult brain [17] and is upregulated during neural progenitor cell differentiation and neuronal maturation [18]. miR-137 is found to increase neural stem cell proliferation and decrease differentiation during early development $[19,20]$. On the other hand, when neurons are differentiated, miR-137 promotes neuronal maturation by facilitating dendritic and axonal morphogenesis, synaptogenesis and spine development [21].

miRNAs have been indicated as important regulators in a number of neurological disorders, ranging from brain and nervous system neoplasms to neurodegenerative diseases such as Alzheimer's disease and Parkinson's disease [22-24]. Potential relationship between
miRNAs and schizophrenia has also been identified in some patients [24]. For example, altered miRNA profiles in prefrontal cortex of schizophrenia patients has been detected from postmortem examination [23]. miRNAs bind to the target mRNAs to repress protein translation or increase mRNA degradation. Further identification of miRNA-targeting genes will help us better understand the mechanisms of neurological diseases, achieving our ultimate goal to develop miRNA-based diagnostic methods and effective therapies for clinical practice.

\section{miRNAs as a Potential Biomarker for Early Detection of Neurological Disorders}

miRNAs were first known to be inside of cells only, serving as regulators/mediators of cellular events. In 2008, they were found in plasma as well [25]. To date, miRNAs have been detected in most biofluids, such as plasma/serum, urine, cerebrospinal fluid (CSF), saliva [26-29]. In contrast to mRNA, extracellular miRNAs are stable and consistent within subjects of the same species [30]. Therefore, it has been proposed that extracellular miRNAs from bio-fluids may be able to serve as biomarkers for various disorders, including neurological diseases. Moreover, extracellular miRNAs alterations could indicate altered biological processes and possible therapies to target the pathological conditions.

Recently, application of miRNAs in easily accessible bio-fluids like plasma/serum as biomarkers for diseases has been widespread. However, current screening techniques used for miRNA biomarker identification are not sufficiently effective and sensitive. A generally used method to identify miRNAs as biomarkers is to compare miRNA profile from patients' bio-fluids with that from control group using miRNA array or next generation sequencing [31]. Although a great number of miRNAs can be analyzed simultaneously, it has been found that the sensitivity is much lower compared with traditional RT-PCR for individual miRNA examination due to the fact that the concentrations of most miRNAs in bio-fluids are very low. To improve the sensitivity, a two-step comparison is performed. Initially, a primary analysis of miRNAs from cells, tissues or organs that are obtained in pathological and normal conditions is performed. In the next step, the differentially expressed miRNAs is to be analyzed and verified [31]. Although there are reports that alteration of miRNAs in bio-fluids are not always consistent with those identified in cells, tissues or organs, this two-step approach has increased the sensitivity and reproducibility in some situations [31].

Similarly, the low concentrations of brain-enriched miRNAs in plasma/serum have resulted in a low detection rate of miRNAs, using current available techniques for identification of biomarkers of neurological diseases. Compared with plasma/serum, identification of 
Page 2 of 3

miRNA biomarkers from the CSF for neurological diseases can be advantageous: CSF is exclusively generated and circulating within the brain; the blood-brain barrier effectively prevents miRNAs generated from other sources entering CSF [31]. After miRNAs were first found in CSF [28], several more studies have demonstrated the presence of miRNAs in CSF and their potentials as biomarkers for neurological disease [32-35]. Further, a study comparing miRNA expression profile from serum and CSF has revealed that miRNA expression pattern is quite consistent among different subjects when miRNAs are from the same type of bio-fluid (serum or CSF). In contrast, the miRNA profile is less similar even the miRNAs are from the same subjects, but in different type of bio-fluids (serum or CSF) [36]. The difference suggests that changes in miRNAs relevant to neurological dysfunctions from plasma/serum could be masked by systemic miRNA changes that are not related to nervous system [36], and alteration of miRNA levels in CSF can be more relevant and sensitive for the early detection of neurological diseases.

\section{Evaluation of miRNA in Neural Stem Cells to Study Neurotoxicity}

It has been a fast progressing field of research to apply miRNAs as indicators to evaluate the severity of damage/injury for chemical/druginduced toxicity. Research experimentation on neurotoxicity, especially developmental neurotoxicity is expensive and time-consuming. Establishing cost-effective and time-efficient experimental models and searching sensitive biomarkers for assessment of developmental neurotoxicity is therefore becoming increasingly necessary. As proposed by the National Research Council in 2007 (National Research Council, 2007), the future developmental neurotoxicity tests will depend mostly on in vitro models. Under such premise, utilization of human-derived neural stem cells may be the most relevant and effective model for understanding the roles of miRNA in mediating neurotoxic effects in human. In fact, the involvement of miRNAs in developmental neurotoxicity has been already observed in studies using human neural stem cell models [37-40]. The obtained results reveal that changes in miRNA expression may be a practical tool for assessing developmental neurotoxicity, understanding the underlined mechanisms, and developing strategies for therapeutic approaches.

\section{Conclusion}

The advances of miRNAs research have enriched our understanding of the CNS development and neurological disorders. Their diverse functions, multiple targets and complicated interacting network imply their profound involvement in the CNS development and functions. When generally the effects of a single miRNA are focused, interaction of multiple miRNAs may cause synergistic or even antagonistic effects. In the CNS, new roles of miRNAs in brain development and neurotoxicity have been just discovered. Although it is still difficult to clarify a cause/effect role of changes in miRNAs for the pathological conditions, application of miRNAs as biomarkers for neurological disorders and neurotoxic testing is promising [41,42].

\section{Disclaimer}

The information in these materials is not a formal dissemination of information by FDA and does not represent agency position or policy.

\section{References}

1. Lee RC, Feinbaum RL, Ambros V (1993) The C. elegans heterochronic gene lin-4 encodes small RNAs with antisense complementarity to lin-14. Cell 75: 843-854.

2. Wightman B, Ha I, Ruvkun G (1993) Posttranscriptional regulation of the heterochronic gene lin-14 by lin- 4 mediates temporal pattern formation in C. elegans. Cell 75: 855-862.

3. He L, Hannon GJ (2004) MicroRNAs: small RNAs with a big role in gene regulation. Nat Rev Genet 5: 522-531.

4. Friedman RC, Farh KK, Burge CB, Bartel DP (2009) Most mammalian mRNAs are conserved targets of microRNAs. Genome Res 19: 92-105.

5. Hayes J, Peruzzi PP, Lawler S (2014) MicroRNAs in cancer: biomarkers, functions and therapy. Trends Mol Med 20: 460-469.

6. Reddy KB (2015) MicroRNA (miRNA) in cancer. Cancer Cell Int 15: 38.

7. Dimmeler S, Nicotera $P$ (2013) MicroRNAs in age-related diseases. EMBO Mol Med 5: 180-190.

8. Wang W, Kwon EJ, Tsai LH (2012) MicroRNAs in learning, memory, and neurological diseases. Learn Mem 19: 359-368.

9. Cao X, Yeo G, Muotri AR, Kuwabara T, Gage FH (2006) Noncoding RNAs in the mammalian central nervous system. Annu Rev Neurosci 29: 77-103.

10. Bak M, Silahtaroglu A, Møller M, Christensen M, Rath MF, et al. (2008) MicroRNA expression in the adult mouse central nervous system. RNA 14: 432-444.

11. Cao DD, Li L, Chan WY (2016) MicroRNAs: Key Regulators in the Central Nervous System and Their Implication in Neurological Diseases. Int J Mol Sci 17.

12. Landgraf P, Rusu M, Sheridan R, Sewer A, Iovino N, et al. (2007) A mammalian microRNA expression atlas based on small RNA library sequencing. Cell 129: 1401-1414.

13. Berezikov E, Thuemmler F, van Laake LW, Kondova I, Bontrop R, et al. (2006) Diversity of microRNAs in human and chimpanzee brain. Nat Genet 38: 1375-1377.

14. Kapsimali M, Kloosterman WP, de Bruijn E, Rosa F, Plasterk RH, et al. (2007) MicroRNAs show a wide diversity of expression profiles in the developing and mature central nervous system. Genome Biol 8: R173.

15. Bian S, Xu TL, Sun T (2013) Tuning the cell fate of neurons and glia by microRNAs. Curr Opin Neurobiol 23: 928-934.

16. Stappert L, Roese-Koerner B, Brüstle O (2015) The role of microRNAs in human neural stem cells, neuronal differentiation and subtype specification. Cell Tissue Res 359: 47-64.

17. Lagos-Quintana M, Rauhut R, Yalcin A, Meyer J, Lendeckel W, et al. (2002) Identification of tissue-specific microRNAs from mouse. Curr Biol 12: 735-739.

18. Deo M, Yu JY, Chung KH, Tippens M, Turner DL (2006) Detection of mammalian microRNA expression by in situ hybridization with RNA oligonucleotides. Dev Dyn 235: 2538-2548.

19. Boyer LA, Plath K, Zeitlinger J, Brambrink T, Medeiros LA, et al. (2006) Polycomb complexes repress developmental regulators in murine embryonic stem cells. Nature 441: 349-353.

20. Shi Y, Zhao X, Hsieh J, Wichterle H, Impey S, et al. (2010) MicroRNA regulation of neural stem cells and neurogenesis. J Neurosci 30: 14931-14936.

21. Smrt RD, Szulwach KE, Pfeiffer RL, Li X, Guo W, et al. (2010) MicroRNA miR-137 regulates neuronal maturation by targeting ubiquitin ligase mind bomb-1. Stem Cells 28: 1060-1070.

22. Nelson PT, Keller JN (2007) RNA in brain disease: no longer just "the messenger in the middle". J Neuropathol Exp Neurol 66: 461-468.

23. Perkins DO, Jeffries CD, Jarskog LF, Thomson JM, Woods K, et al. (2007) microRNA expression in the prefrontal cortex of individuals with schizophrenia and schizoaffective disorder. Genome Biol 8: R27.

24. Hansen T, Olsen L, Lindow M, Jakobsen KD, Ullum H, et al. (2007) Brain expressed microRNAs implicated in schizophrenia etiology. PLoS One 2: e873. 
Citation: Liu F, Wang C (2016) MicroRNAs Role in the Central Nervous System Development and Abnormalities. J Pharmacogenomics Pharmacoproteomics 7: e154. doi:10.4172/2153-0645.1000e154

Page 3 of 3

25. Lawrie CH, Gal S, Dunlop HM, Pushkaran B, Liggins AP, et al. (2008) Detection of elevated levels of tumour-associated microRNAs in serum of patients with diffuse large B-cell lymphoma. Br J Haematol 141: 672-675.

26. Mitchell PS, Parkin RK, Kroh EM, Fritz BR, Wyman SK, et al. (2008) Circulating microRNAs as stable blood-based markers for cancer detection. Proc Natl Acad Sci USA 105: 10513-10518.

27. Hanke M, Hoefig K, Merz H, Feller AC, Kausch I, et al. (2010) A robust methodology to study urine microRNA as tumor marker: microRNA-126 and microRNA-182 are related to urinary bladder cancer. Urol Oncol 28 655-661.

28. Cogswell JP, Ward J, Taylor IA, Waters M, Shi Y, et al. (2008) Identification of miRNA changes in Alzheimer's disease brain and CSF yields putative biomarkers and insights into disease pathways. J Alzheimers Dis 14: 27-41.

29. Gallo A, Tandon M, Alevizos I, Illei GG (2012) The majority of microRNAs detectable in serum and saliva is concentrated in exosomes. PLoS One 7: e30679.

30. Chen X, Ba Y, Ma L, Cai X, Yin Y, et al. (2008) Characterization of microRNAs in serum: a novel class of biomarkers for diagnosis of cancer and other diseases. Cell Res 18: 997-1006.

31. Sheinerman KS, Umansky SR (2013) Circulating cell-free microRNA as biomarkers for screening, diagnosis and monitoring of neurodegenerative diseases and other neurologic pathologies. Front Cell Neurosci 7: 150.

32. Alexandrov PN, Dua P, Hill JM, Bhattacharjee S, Zhao Y, et al. (2012) microRNA (miRNA) speciation in Alzheimer's disease (AD) cerebrospinal fluid (CSF) and extracellular fluid (ECF). Int J Biochem Mol Biol 3: 365-373.

33. Lukiw WJ, Alexandrov PN, Zhao Y, Hill JM, Bhattacharjee S (2012) Spreading of Alzheimer's disease inflammatory signaling through soluble micro-RNA. Neuroreport 23: 621-626.
34. Kiko T, Nakagawa K, Tsuduki T, Furukawa K, Arai H, et al. (2014) MicroRNAs in plasma and cerebrospinal fluid as potential markers for Alzheimer's disease. J Alzheimers Dis 39: 253-259.

35. Teplyuk NM, Mollenhauer B, Gabriely G, Giese A, Kim E, et al. (2012) MicroRNAs in cerebrospinal fluid identify glioblastoma and metastatic brain cancers and reflect disease activity. Neuro Oncol 14: 689-700.

36. Burgos KL, Javaherian A, Bomprezzi R, Ghaffari L, Rhodes S, et al. (2013) Identification of extracellular miRNA in human cerebrospinal fluid by next-generation sequencing. RNA 19: 712-722.

37. Twaroski DM, Yan Y, Olson JM, Bosnjak ZJ, Bai X (2014) Down-regulation of microRNA-21 is involved in the propofol-induced neurotoxicity observed in human stem cell-derived neurons. Anesthesiology 121: 786-800.

38. Pallocca G, Fabbri M, Nerini-Molteni S, Pistollato F, Zagouraet D, et al (2014) Changes in miRNA Expression Profiling during Neuronal Differentiation and Methyl Mercury-Induced Toxicity in Human in Vitro Models. Toxics 2: 443-463.

39. Pallocca G, Fabbri M, Sacco MG, Gribaldo L, Pamies D, et al. (2013) miRNA expression profiling in a human stem cell-based model as a tool for developmental neurotoxicity testing. Cell Biol Toxicol 29: 239-257.

40. Smirnova L, Block K, Sittka A, Oelgeschläger M, Seiler AE, et al. (2014) MicroRNA profiling as tool for in vitro developmental neurotoxicity testing: the case of sodium valproate. PLoS One 9: e98892.

41. Yang X, Salminen WF, Shi Q, Greenhaw J, Gill PS, et al. (2015) Potential of extracellular microRNAs as biomarkers of acetaminophen toxicity in children. Toxicol Appl Pharmacol 284: 180-187.

42. Deng Y, Ai J, Guan X, Wang Z, Yan B, et al. (2014) MicroRNA and messenger RNA profiling reveals new biomarkers and mechanisms for RDX induced neurotoxicity. BMC Genomics 15: S1. 